\title{
Performance of Stone Columns in Cohesive Soil
}

\author{
Adel Hanna and Mahmoud Khalifa \\ Concordia University, Canada \\ 1455 Boulevard de Maisonneuve O, Montréal, QC \\ hanna@civil.concordia.ca
}

Stone columns are widely used as a soil improvement technique for highways and embankments. Stone columns considered as the most cost-effective and environmental-friendly soil improvement technique. Stone columns are also used as drainage to reduce the consolidation period, which will accordingly increase the bearing capacity and reducing the settlement and further the liquefaction potential.

The current design theories to estimate the bearing capacity of a group of stone columns are based on the unit cell or homogenized material concepts, which neglect the effect of the columns interactions and installation technique. This paper presents an experimental investigation, together with numerical modelling to examine the performance of a single and group of stone columns subjected to vertical stresses. An analytical model was developed to capture the effect of stone columns arrangement and the mode of failure within the column and the soft clay material.

Experimentally, single and group of stone columns were investigated in a large-scale experimental setup. The testing program is divided into three steps; filling the testing tank with the clay, installing the stone columns in the clay bed, and then extracting samples of the reinforced soil (a block of stone columns surrounded by the soft clay loading) to be tested in the triaxial apparatus. The results showed that the mode of failure of the reinforced soil depends on the columns spacing and the strength of the materials of the columns and the surrounding soil.

Numerically, a high-fidelity 3D finite element model was developed to examine the effect of the governing parameters affecting the bearing capacity of the group. The model was validated by the present experimental results and by those available in the literature. The numerical model was used to simulate the actual driving process during columns installation. The model was then used to predict the actual failure plane under a rigid footing reinforced by stone columns for a given geometry/soil condition.

An analytical model was developed utilizing the actual failure plane deduced from the numerical model to develop a theory to predict the bearing capacity of the reinforced soil. The theory developed was validated by the results obtained from the numerical model and those available in the literature. 